Research Article

\title{
Comprehensive Experimental Study of Affecting Factors on Rectangular Roadway Stability
}

\author{
Zhongcheng Qin, ${ }^{1}$ Bin Cao ${ }^{1},{ }^{1}$ Tan Li, ${ }^{1}$ Xin Yu, $^{2}$ and Guangbo Chen ${ }^{1}$ \\ ${ }^{1}$ School of Mining and Safety Engineering, Shandong University of Science and Technology, Qingdao 266590, China \\ ${ }^{2}$ School of Mechanics and Civil Engineering, China University of Mining \& Technology-Beijing, Beijing 100083, China \\ Correspondence should be addressed to Bin Cao; 18306483735@163.com
}

Received 26 August 2019; Revised 29 May 2020; Accepted 11 June 2020; Published 28 June 2020

Academic Editor: Giovanni Garcea

Copyright (c) 2020 Zhongcheng Qin et al. This is an open access article distributed under the Creative Commons Attribution License, which permits unrestricted use, distribution, and reproduction in any medium, provided the original work is properly cited.

\begin{abstract}
In this paper, two methods of orthogonal numerical simulation test and similar material simulation test are used to study the influence of five factors on the stability of rectangular roadway: roadway width, roadway height, roadway buried depth, lateral pressure coefficient of surrounding rock, and comprehensive strength of surrounding rock. The results show that five factors have influence on the stability of roadway, but the degree of influence is different. The depth of the tunnel and the coefficient of the side pressure of the surrounding rock are positively correlated with the stability of the tunnel; the comprehensive strength of the surrounding rock is negatively correlated with the stability of the tunnel, but the correlation between the width and height of the tunnel and the stability of the tunnel is not obvious. The results of orthogonal numerical simulation test and similar material simulation test verify each other. The results of the field practice of the Fucun coal mine are basically consistent with the results of the two test methods, which shows that the research results have a certain guiding effect on the field roadway support.
\end{abstract}

\section{Introduction}

The factors influencing the roadway stability majorly arise from two aspects: (1) natural conditions which include the burial depth of roadway, the strength of surrounding rock, hydrological environments, etc.; (2) mining techniques, involving the roadway cross section shape, dimensions, roadway arrangement type, supporting method, etc. [1].This paper presents a study on the effect of the abovementioned factors on the roadway stability.

The ratio of width and height of rectangular roadway can directly influence the stress state of surrounding rock; the lateral pressure coefficient has an obvious effect on the distribution of the plastic zone of surrounding rock; and the closer the width-height ratio and the lateral pressure coefficient are, the smaller the stress concentration factor of roadway is [2, 3]. From the perspective of Kang [4], the deformation and damage of the ribs of roadway are primarily subjected to the vertical stress, and the deformation and damage of roof and floor are determined by the horizontal stress which is the key factor. In the viewpoint of Li et al. [5], the range of plastic failure zone enlarges and the deformation increases with the increment of the burial depth of roadway. And the vertical stress zone of roof and floor expands, while the core of horizontal stress moves into the deeper rock mass. On the contrary, the horizontal stress zone of ribs expands and the core of vertical stress moves into the deeper rock. Jing et al. [6] hold the opinion that the strength of surrounding rock is composed of the peak strength and the residual strength of rock mass. When the residual strength is less than $5 \% \sim 10 \%$ of the peak strength, the plastic zone increases dramatically as the residual strength decreases. Through comprehensive analysis of the above literature, it can be found that, at present, the factors affecting the stability of the roadway are studied only from a single point of view, without comprehensive analysis and discussion of many factors affecting the stability of the roadway. In this paper, based on the principle of orthogonal test, a numerical simulation test and a similar material simulation test scheme are developed 
to comprehensively analyze the width, height, burial depth, and lateral pressure coefficient of the surrounding rock The influence of 5 factors of the comprehensive strength of the surrounding rock on the stability of the roadway and the comparison between the two test results and the field practice results put forward a new method to study the stability of the roadway for the reference of the field production of the coal mine.

\section{Theoretical Analysis of the Roadway Stability}

2.1. Mechanical Analysis of the Roof Stability. According to material mechanics, roof can be simplified as uniformly and axially loaded beam fixed at two ends, as shown in Figure 1.

Under the co-action of deadweight $q$ and axial thrust $N$, the roof beam will be subjected to buckling failure. The approximate differential equation of deflection curve is

$$
\frac{\mathrm{d}^{2} \omega}{\mathrm{d} x^{2}}=\frac{M_{x}}{E I},
$$

where $\omega$ is the beam deflection; $M_{x}$ is the resultant moment of a certain section whose outward normal is the $x$-axis; $E$ is the elastic modulus; $I$ is the inertia moment of the cross section to neutral axis.

In which

$$
M_{x}=\frac{q a^{2}}{12}+N \omega-\frac{q x^{2}}{2}+\frac{q a}{2} x,
$$

where $a$ is the span of beam AB.

Substituting (2) into (1) and rearranging yield

$$
\frac{\mathrm{d}^{2} \omega}{\mathrm{d} x^{2}}-\frac{N}{E I} \omega=\frac{1}{E I}\left(\frac{q a^{2}}{12}-\frac{q x^{2}}{2}+\frac{q a}{2} x\right) .
$$

Putting $\beta^{2}=N / E I$ into (3),

$$
\frac{\mathrm{d}^{2} \omega}{\mathrm{d} x^{2}}-\beta^{2} \omega=\frac{q \beta^{2}}{2 N}\left(\frac{a^{2}}{6}-x^{2}+a x\right) .
$$

Solving differential equation (4),

$$
\omega=c_{1} e^{\beta x}+c_{2} e^{-\beta x}+\frac{q}{2 N}\left(x^{2}-a x+\frac{12-\beta^{2} a^{2}}{6 \beta^{2}}\right) .
$$

According to the boundary conditions,

$$
\left\{\begin{array}{l}
\left.\omega\right|_{x=0}=0, \\
\left.\frac{\mathrm{d} \omega}{\mathrm{d} x}\right|_{x=(a / 2)}=0 .
\end{array}\right.
$$

Substituting (6) into (7),

$$
\left\{\begin{array}{l}
c_{1}=\frac{q\left(\beta^{2} a^{2}-12\right)}{12 N \beta^{2}\left(1+e^{\beta a}\right)}, \\
c_{2}=c_{1} e^{\beta a} .
\end{array}\right.
$$

Substituting (7) into (5),

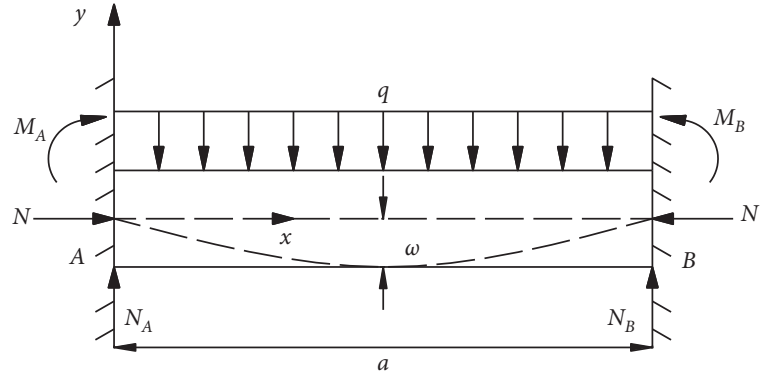

Figure 1: Simplified mechanical model of roof.

$$
\omega=\frac{q\left(\beta^{2} a^{2}-12\right)}{12 N \beta^{2}\left(1+e^{\alpha a}\right)}\left(e^{\beta a}+e^{\beta(a-x)}\right)+\frac{q}{2 N}\left(x^{2}-a x+\frac{12-\beta^{2} a^{2}}{6 \beta^{2}}\right) .
$$

According to (8), the roof stability not only relates to deadweight $q$ and axial thrust $N$, but also associates with the roof span $a$. While the axial thrust $N$ is generated by horizontal stress which has a relation with burial depth $H$ and lateral pressure coefficient $\lambda, H$ and $\lambda$ also have an effect on the roof stability.

2.2. Mechanical Analysis of the Rib Stability. Coal seam is characterized by being inhomogeneous and stratified. Generally, the strength of roof and floor is harder than the strength of coal seam. For the reason of the cohesion and internal friction angle in the interface between coal seam and roof, floor (using interface for short in the following description) is smaller than that in the coal seam; the coal-body in the stress limiting equilibrium zone $A B C D$ is going to move towards the void after excavating without providing any support. As a result, the movement will lead to the instability of rock mass (coal-body) of ribs [7]. The simplified mechanical model of coal-body in ribs is shown in Figure 2.

See Figure 3; a coal unit is taken from stress-limiting equilibrium zone $A B C D$.

According to static equilibrium conditions,

$$
T(x)+2 \tau \cdot \mathrm{d} x \cdot 1-T(x)-\mathrm{d} T(x)=0,
$$

where $T(x)$ is the axial thrust at $x$ of $x$-coordinate; $\tau$ is shear stress on the interface.

Putting $q=2 \tau$ into (9) and rearranging yield

$$
q=\frac{\mathrm{d} T(x)}{\mathrm{d} x}
$$

where $q$ is shear stress collection degree.

According to Hooke's law,

$$
T(x)=b \cdot 1 \cdot \lambda k_{x} \gamma H=b E \frac{\mathrm{d} s}{\mathrm{~d} x},
$$

where $b$ is the roadway width; $\lambda$ is the lateral pressure coefficient; $k_{x}$ is the stress concentration factor at $x$ of $x$-coordinate; $\gamma$ is the bulk density of rock; $H$ is the burial depth of roadway; $E$ is the elastic modulus of coal; and $s$ is the displacement caused by axial thrust $T(x)$. 


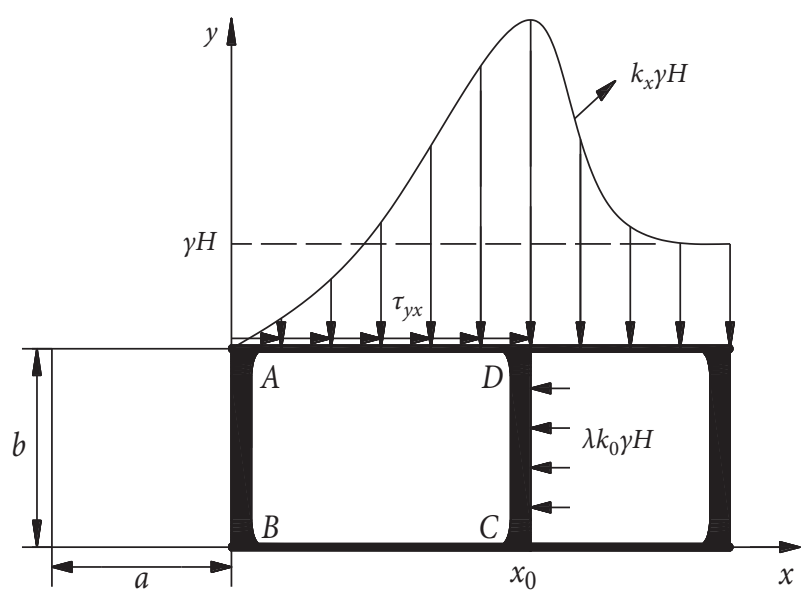

Figure 2: Simplified mechanical model of rib coal-body.

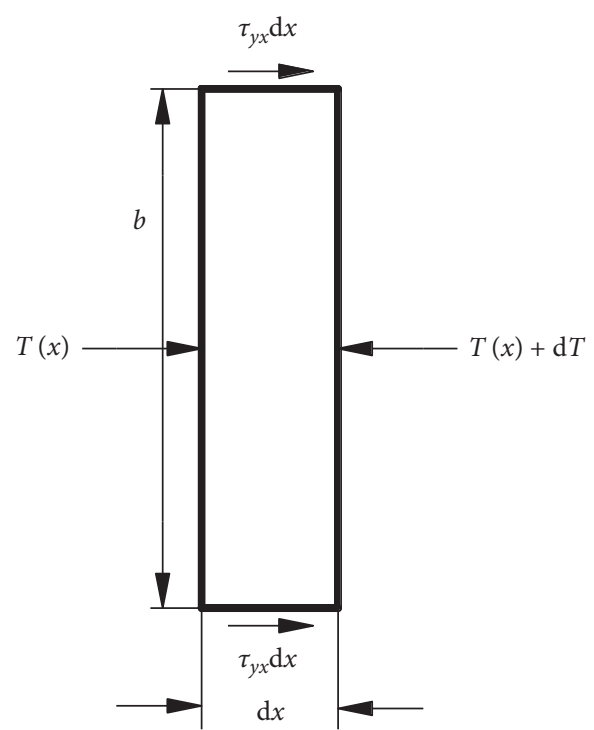

FIGURE 3: Simplified mechanical model of coal unit.

Substituting (11) into (10),

$$
q=b E \frac{\mathrm{d}^{2} s}{\mathrm{~d} x^{2}}
$$

Assuming that $q$ is in linearity with $s$, then

$$
q=A s,
$$

where $A$ is the shear stiffness coefficient, which means the shear stress caused by unit displacement in the unit coalbody, of the interface. (13),

Putting $\alpha^{2}=A / b E$ into simultaneous equations (12) and

$$
\frac{\mathrm{d}^{2} s}{\mathrm{~d} x^{2}}-\alpha^{2} s=0
$$

Solving (14) yields

$$
s=c_{3} e^{\alpha x}+c_{4} e^{-\alpha x}
$$

According to the boundary conditions,

$$
\left\{\begin{array}{l}
\left.\frac{\mathrm{d} s}{\mathrm{~d} x}\right|_{x=0}=0 \\
\left.\frac{\mathrm{d} s}{\mathrm{~d} x}\right|_{x=x_{0}}=\frac{T\left(x_{0}\right)}{b E} .
\end{array}\right.
$$

Substituting (16) into (15) yields

$$
\left\{\begin{array}{l}
c_{3}=c_{4}, \\
c_{3}=\frac{T\left(x_{0}\right)}{b E \alpha\left(e^{\alpha x_{0}}-e^{-\alpha x_{0}}\right)},
\end{array}\right.
$$

Substituting (17) into (15) yields

$$
s=\frac{T\left(x_{0}\right)\left(e^{\alpha x}+e^{-\alpha x}\right)}{b E \alpha\left(e^{\alpha x_{0}}-e^{-\alpha x_{0}}\right)} .
$$

According to (18), the ribs' displacement $s$ is not only related to axial thrust $T\left(x_{0}\right)$ and elastic modulus $E$, but also has a relationship with roadway height $b$. The bigger the height $b$ is, the smaller the ribs' displacement $s$ will be, with other variables being constant.

2.3. Comprehensive Strength of Surrounding Rock. It is postulated that the roadway has a rectangular section and locates in the flat coal seam, roof and floor are constituted of hard strata like sandstones, etc., the rib is coal seam, additionally, there are no geological structures such as fault, etc., and the rock (coal) layers are well integrated.

Comprehensive strength of surrounding rock (using CSSR as abbreviation in the following text) is defined as the overall strength of roof, ribs, and floor rock mass of roadway, which reflects the general stability of surrounding rock. Specifically, CSSR is a weighted average of uniaxial compressive strength, tensile strength, and shear strength of rock, and its unit is MPa. CSSR is given by

$$
\sigma_{i}=\alpha^{\mathrm{T}} A \beta,
$$

where $\sigma_{i}$ is CSSR; $\alpha^{\mathrm{T}}=\left(a_{1}, a_{2}, a_{3}\right)$ is the weight vector of each strength (uniaxial compressive strength, tensile strength, and shear strength) to the overall strength of a single rock layer; $\beta=\left(b_{1}, b_{2}, b_{3}\right)^{\mathrm{T}}$ is the weight vector of each rock layer (roof, rib, and floor) to CSSR; and $A=\left[\begin{array}{ccc}\sigma_{c 1} & \sigma_{c 2} & \sigma_{c 3} \\ \sigma_{t 1} & \sigma_{t 2} & \sigma_{t 3} \\ \tau_{1} & \tau_{2} & \tau_{3}\end{array}\right]$ is the strength matrix of surrounding rock.

$\alpha^{\mathrm{T}}$ in (1) is determined by AHP [8].Uniaxial compressive strength, tensile strength, and shear strength are served as the evaluation indexes of the overall strength of a certain stratum. The hierarchy diagram is shown in Figure 4.

According to a number of rock mechanical experiments, theoretical analysis, and numerical simulation $[9,10]$, the 3 order judgment matrix has been formulated, with the stratum overall strength evaluation indexes mentioned above with reference to the $1 \sim 9$ scaling law. 


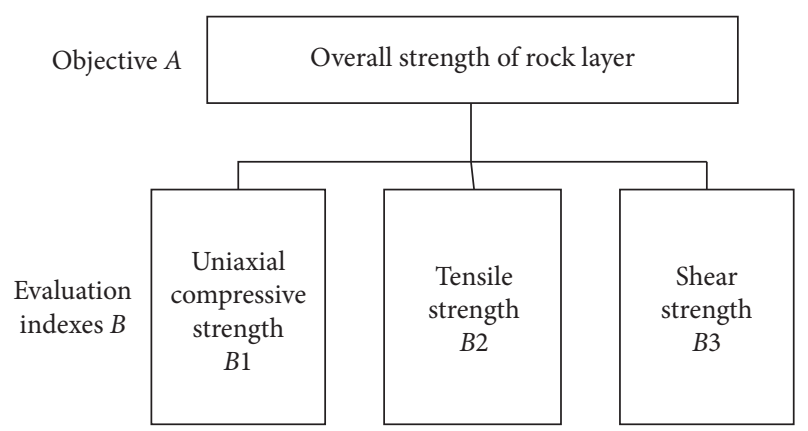

FIgURE 4: Hierarchy diagram of stratum overall strength.

$$
p_{A-B}=\left[\begin{array}{lll}
1 & 6 & 3 \\
\frac{1}{6} & 1 & \frac{1}{2} \\
\frac{1}{3} & 2 & 1
\end{array}\right] .
$$

The maximum characteristic value of (20) is $\lambda_{\max }=3$. Calculating the feature vector and normalizing, it yields

$$
\alpha^{\mathrm{T}}=(0.661,0.111,0.222) \text {. }
$$

Since (20) is a consistent matrix, it surely satisfies the consistency condition. In terms of $\alpha^{\mathrm{T}}$, the weight of evaluation index of overall strength of stratum is illustrated in Figure 5.

The weight vector of each stratum to the overall strength of surrounding rock can also be calculated in the same way as the calculation of $\alpha^{\mathrm{T}}$.

$$
\beta=(0.500,0.278,0.222)^{\mathrm{T}} \text {. }
$$

The weight values of roof, ribs, and floor are 50\%, 27.8\%, and $22.2 \%$, respectively, as shown in Figure 6.

\section{Orthogonal Numerical Simulation}

3.1. Numerical Model. The length, width, and height of the $3 \mathrm{D}$ numerical model established by using FLAC $\mathrm{CD}^{3 \mathrm{D}}$ are $35 \mathrm{~m}$, $8 \mathrm{~m}$, and $35 \mathrm{~m}$, respectively. The rectangular roadway is situated in the middle of the model. On the upper surface of the model, the corresponding uniform vertical compressive stress is applied according to the different buried depths of the roadway (the uniform vertical compressive stress is the buried depth of the roadway multiplied by the average bulk density of the rock). Horizontal compressive stress which varies with the depth is applied to both sides of the model. The horizontal and vertical displacement of the lower surface of the model is fixed. Mohr-Coulomb yield criterion is used in the model, as shown in Figure 7. The selection of mechanical parameters of the model is shown in Table 1 .

3.2. Evaluation Index. Comprehensive deformation of roadway (CDR) is developed to evaluate the effect of roadway's width and height, burial depth, lateral pressure

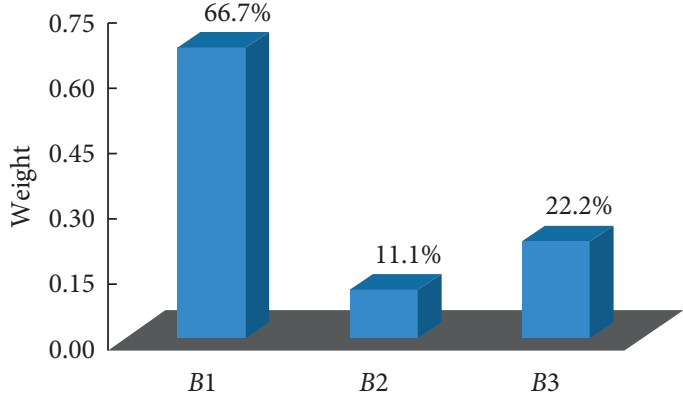

FIGURE 5: Weight value histogram of each evaluation index of the overall strength of stratum.

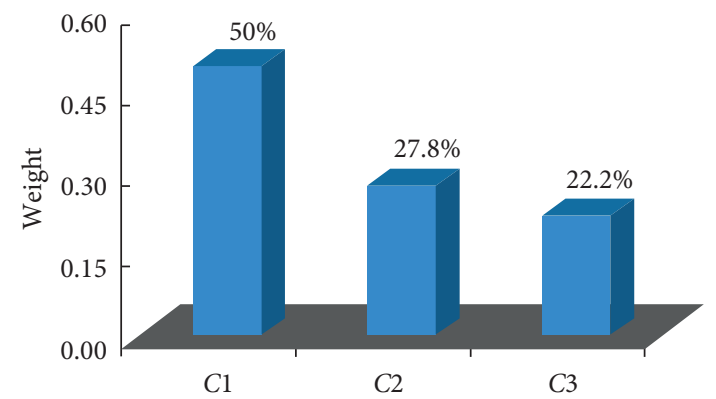

FIGURE 6: Weight value histogram of each stratum to CSSR.

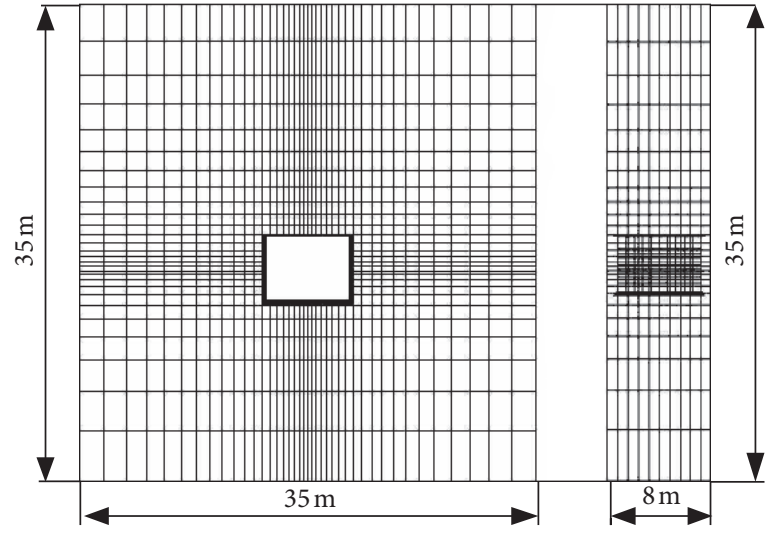

Figure 7: Schematic diagram of the 3D numerical model.

coefficient, and CSSR on the stability of roadway. The smaller the value of CDR is, the less effect on the roadway stability will be. Its unit is $\mathrm{mm}$.

$$
D_{c}=D \beta \text {, }
$$

where $D_{c}$ is CDR; $D=\left(d_{1}, d_{2}, d_{3}\right)$, the weight vector, is composed of displacements of roof, ribs, and floor.

3.3. Orthogonal Experiment. Orthogonal experiment is a mathematical statistics method developed to arrange experiment and analyze the data gained from the experiment, by using orthogonal array [11-14]. Orthogonal experiment has 2 prominent features: (1) different levels of each factor appear in the experiment with the same number of times; (2) different 
TABLE 1: The mechanical parameters of model.

\begin{tabular}{lccccc}
\hline Lithology & $\begin{array}{c}\text { Bulk modulus } \\
(\mathrm{GPa})\end{array}$ & $\begin{array}{c}\text { Shear modulus } \\
(\mathrm{GPa})\end{array}$ & $\begin{array}{c}\text { Strength of extension } \\
(\mathrm{MPa})\end{array}$ & $\begin{array}{c}\text { Cohesion } \\
(\mathrm{MPa})\end{array}$ & $\begin{array}{c}\text { Internal friction angle } \\
\left({ }^{\circ}\right)\end{array}$ \\
\hline Medium & 10.6 & 7.27 & 2.43 & 2.05 & 33 \\
sandstone & 14.5 & 5.95 & 2.13 & 2.45 & 36 \\
Fine sandstone & 4.58 & 2.59 & 0.75 & 0.84 & 30 \\
Mudstone & 4.17 & 2.27 & 1.15 & 1.07 & 32 \\
Sandy mudstone & 4.03 & 1.65 & 0.54 & 0.95 & 31 \\
Coal seam & & & & \\
\hline
\end{tabular}

combinations of any levels of any two factors all appear in the experiment. It also has advantages of convenient operation, high efficiency, etc.

Five factors, including roadway width and height, burial depth, lateral pressure coefficient, and CSSR, each of which is chosen at 5 different levels, are selected in the orthogonal experiment to simulate the deformation of roadway [15-30]. Orthogonal array $\mathrm{L}_{25}\left(5^{6}\right)$ is employed in the experiment. Factors and levels are shown in Table 2, and the experiment scheme is shown in Table 3.

According to Table 3, establishing 25 numerical simulation models, the 5 factors of each model are determined by the corresponding experiment no., and all other conditions are the same. CDR is served as the evaluation index, and the experiment results are shown in Table 3.

\section{Analysis of Orthogonal Numerical Simulation Results}

Extremum difference analysis, which is also known as intuitive analysis, is used in drawing any conclusions of the experiment by analyzing the range and trend chart. Extremum difference analysis is commonly used in orthogonal experiment, since it is straightforward and intuitive. According to the results from Table 3, the mean and range of different levels of each factor can be calculated. The visual analysis results of comprehensive deformation of roadway are shown in Table 4.

According to the values in the last row of Table 4, arranging them in descending order is $H>\sigma_{i}>\lambda>a>b$, which implies that burial depth is most influential, while CSSR and lateral pressure coefficient are less, and roadway width and height are the least.

According to Table 4, the range analysis diagram is illustrated in Figure 8, in order to analyze the trend more visually and reflect the effect more vividly.

It can be concluded from Figure 8 that roadway width, height, burial depth, lateral pressure coefficient, and CSSR all have effects on the stability of roadway. However, the significance is not the same. Burial depth and lateral pressure coefficient (when it is less than 1.0) are positively correlated with the roadway stability, while CSSR is negatively correlated with the roadway stability, and there is no obvious correlation between roadway width and height and roadway stability.

CDR increases sharply (from $26.28 \mathrm{~mm}$ to $138.74 \mathrm{~mm}$ ) with the burial depth increase from $200 \mathrm{~m}$ to $1000 \mathrm{~m}$. CDR decreases rapidly initially, subsequently changing
TABLE 2: Factors and levels of orthogonal numerical simulation experiment.

\begin{tabular}{lccccc}
\hline Levels & $\begin{array}{c}A \\
a(\mathrm{~m})\end{array}$ & $\begin{array}{c}B \\
b(\mathrm{~m})\end{array}$ & $\begin{array}{c}C \\
H(\mathrm{~m})\end{array}$ & $\begin{array}{c}D \\
\lambda\end{array}$ & $\begin{array}{c}E \\
\sigma_{i}(\mathrm{MPa})\end{array}$ \\
\hline 1 & 3 & 2.5 & 200 & 0.3 & 8 \\
2 & 3.5 & 3 & 400 & 0.6 & 28 \\
3 & 4 & 3.5 & 600 & 0.9 & 48 \\
4 & 4.5 & 4 & 800 & 1.2 & 68 \\
5 & 5 & 4.5 & 1000 & 1.5 & 88 \\
\hline
\end{tabular}

TABLE 3: The scheme for orthogonal experiment.

\begin{tabular}{|c|c|c|c|c|c|c|}
\hline \multirow{2}{*}{$\begin{array}{l}\text { Experiment } \\
\text { no. }\end{array}$} & \multicolumn{5}{|c|}{ Factors } & \multirow{2}{*}{$\begin{array}{c}\text { Index } \\
D_{c} \\
(\mathrm{~mm})\end{array}$} \\
\hline & $a(\mathrm{~m})$ & $b(\mathrm{~m})$ & $H(\mathrm{~m})$ & $\lambda$ & $\begin{array}{c}\sigma_{i} \\
(\mathrm{MPa})\end{array}$ & \\
\hline 1 & $3(1)$ & $\begin{array}{l}2.5 \\
(1)\end{array}$ & $200(1)$ & $\begin{array}{l}0.3 \\
(1)\end{array}$ & $8(1)$ & 14.9 \\
\hline 2 & 3 & $3(2)$ & $400(2)$ & $\begin{array}{l}0.6 \\
(2)\end{array}$ & $28(2)$ & 38.3 \\
\hline 3 & 3 & $\begin{array}{l}3.5 \\
(3)\end{array}$ & $600(3)$ & $\begin{array}{l}0.9 \\
(3)\end{array}$ & $48(3)$ & 55.5 \\
\hline 4 & 3 & $4(4)$ & $800(4)$ & $\begin{array}{l}1.2 \\
(4)\end{array}$ & $68(4)$ & 100 \\
\hline 5 & 3 & $\begin{array}{l}4.5 \\
(5)\end{array}$ & $\begin{array}{c}1000 \\
(5)\end{array}$ & $\begin{array}{l}1.5 \\
(5)\end{array}$ & $88(5)$ & 93.5 \\
\hline 6 & $\begin{array}{l}3.5 \\
(2)\end{array}$ & 2.5 & 400 & 0.9 & 68 & 48.1 \\
\hline 7 & 3.5 & 3 & 600 & 1.2 & 88 & 60 \\
\hline 8 & 3.5 & 3.5 & 800 & 1.5 & 8 & 243.2 \\
\hline 9 & 3.5 & 4 & 1000 & 0.3 & 28 & 94.7 \\
\hline 10 & 3.5 & 4.5 & 200 & 0.6 & 48 & 16.4 \\
\hline 11 & $4(3)$ & 2.5 & 600 & 1.5 & 28 & 94.6 \\
\hline 12 & 4 & 3 & 800 & 0.3 & 48 & 79.5 \\
\hline 13 & 4 & 3.5 & 1000 & 0.6 & 68 & 113 \\
\hline 14 & 4 & 4 & 200 & 0.9 & 88 & 37.8 \\
\hline 15 & 4 & 4.5 & 400 & 1.2 & 8 & 76.8 \\
\hline 16 & $\begin{array}{l}4.5 \\
(4)\end{array}$ & 2.5 & 800 & 0.6 & 88 & 95.6 \\
\hline 17 & 4.5 & 3 & 1000 & 0.9 & 8 & 260.5 \\
\hline 18 & 4.5 & 3.5 & 200 & 1.2 & 28 & 29.5 \\
\hline 19 & 4.5 & 4 & 400 & 1.5 & 48 & 59.5 \\
\hline 20 & 4.5 & 4.5 & 600 & 0.3 & 68 & 42.1 \\
\hline 21 & $5(5)$ & 2.5 & 1000 & 1.2 & 48 & 132 \\
\hline 22 & 5 & 3 & 200 & 1.5 & 68 & 32.8 \\
\hline 22 & 5 & 3.5 & 400 & 0.3 & 88 & 40.5 \\
\hline 24 & 5 & 4 & 600 & 0.6 & 8 & 96.8 \\
\hline 25 & 5 & 4.5 & 800 & 0.9 & 28 & 110 \\
\hline
\end{tabular}

moderately. CSSR adds from $8 \mathrm{MPa}$ to $28 \mathrm{MPa}$, increased by $250 \%$, and CDR decreases from $138.44 \mathrm{~mm}$ to $73.42 \mathrm{~mm}$, decreasing by $47 \%$. CSSR keeps increasing from $28 \mathrm{MPa}$ to 
TABLE 4: Extremum difference analysis of comprehensive deformation of roadway.

\begin{tabular}{lccccc}
\hline \multirow{2}{*}{ Average } & $A$ & $B$ & $C$ & $D$ & $E$ \\
& $a(\mathrm{~m})$ & $b(\mathrm{~m})$ & $H(\mathrm{~m})$ & 54.34 & 72.02 \\
$\sigma_{i}(\mathrm{MPa})$
\end{tabular}

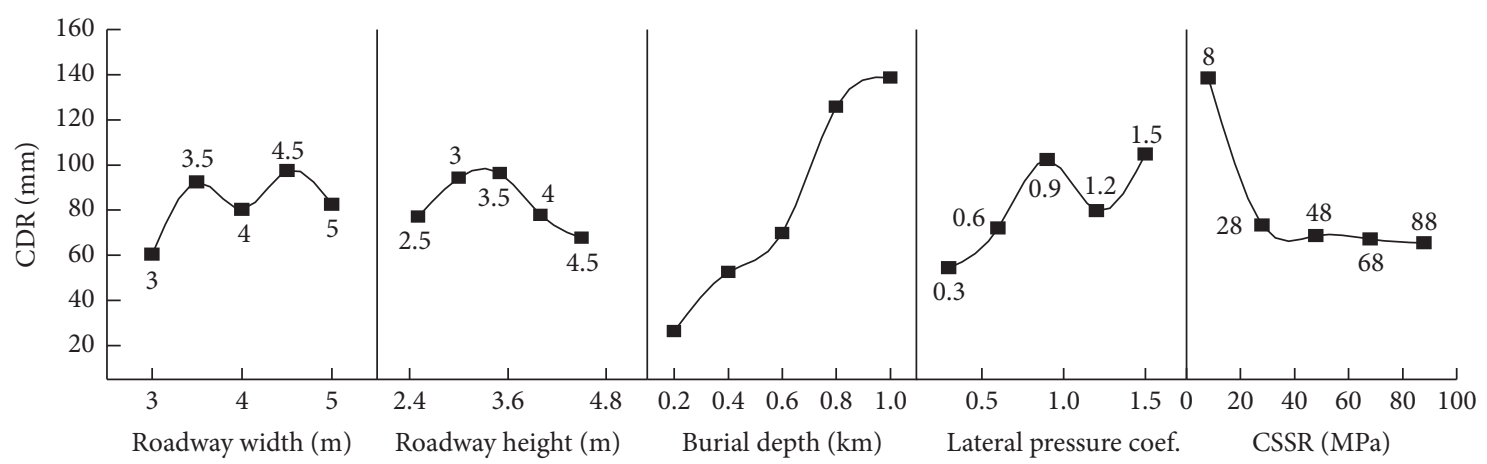

FIGURE 8: The effect of each factor on the roadway stability.

$88 \mathrm{MPa}$ (214.3\%); CDR decreases from $73.42 \mathrm{~mm}$ to $65.48 \mathrm{~mm}(10.8 \%)$, which implies there is an "inflection point" (about $30 \mathrm{MPa}$ ). When CSSR is less than $30 \mathrm{MPa}$, its influence on CDR is relatively obvious; when CSSR is more than $30 \mathrm{MPa}$, the effect is remarkably weakened.

\section{Similar Material Simulation Experiment}

5.1. Brief Introduction to Similar Materials Simulated Experiments. Similar material simulation is a kind of scientific experiment. It is one of the ways for people to explore and understand the law of ground pressure. Artificial materials are used to simulate the physical and mechanical properties of natural rocks, and a mine model is made according to a certain scale. Then, the tunnel is excavated in the model, and the deformation and damage of the model are recorded, so as to analyze and speculate the situation in the original mine prototype [31-33].

In order to make what happens in the model truly reflects what happens in the prototype, according to the nature of the problem, prototype and model similarity must have the following conditions.

(1) Geometric similarity: the geometry of the model should be comparable to that of the prototype. Therefore, the size of the prototype, including length, width, and height, must be reduced or enlarged in a definite proportion to make the model

(2) Similar motion: in the model and prototype, the motion of all corresponding points is comparable; that is, the velocity, acceleration, and time of each corresponding point are required to be proportional
(3) Dynamic similarity: all forces acting on the model are to be similar to those of the prototype.

5.2. Experimental Instruments and Materials. The main instruments used in this paper are three-dimensional similar material simulation testbed of East China University of Technology, as shown in Figure 9. Other instruments include displacement sensor, load sensor, balance weighing up to $1000 \mathrm{~g}$, minimum $0.01 \mathrm{~g}$, caliper accuracy of $0.02 \mathrm{~mm}$, steel ruler, mixing pot, and measuring cylinder.

Similar materials used throughout this paper are cement mortar mixed with quartz sand, cement, gypsum, and water, with a density of about $2.0 \mathrm{~g} / \mathrm{cm}^{3}$, and layered with mica powder.

\subsection{Similar Material Simulation Experiment Processes}

5.3.1. Model Parameters. The model parameter test is carried out on a three-dimensional parallel material simulation test bench. The size of the test bench is $1500 \mathrm{~mm}$ $* 1500 \mathrm{~mm} \mathrm{~m} * \mathrm{~m} 1500 \mathrm{~mm}$ (length $\mathrm{m} *$ mwidth $\mathrm{m} *$ height). The cramped space is composed of six pressure plates, i.e., upper, lower, front and rear, and left and right. The excavation openings are restricted to the front and rear pressure plates, and the openings are sealed by bolts and iron plates when loading.

5.3.2. Model Materials and Production. According to the actual stratigraphic conditions, 25 models of similar materials were established through different material ratios, forming the surrounding rock of the rectangular roadway. The geometric similarity ratio of the model is $1: 100$. The 


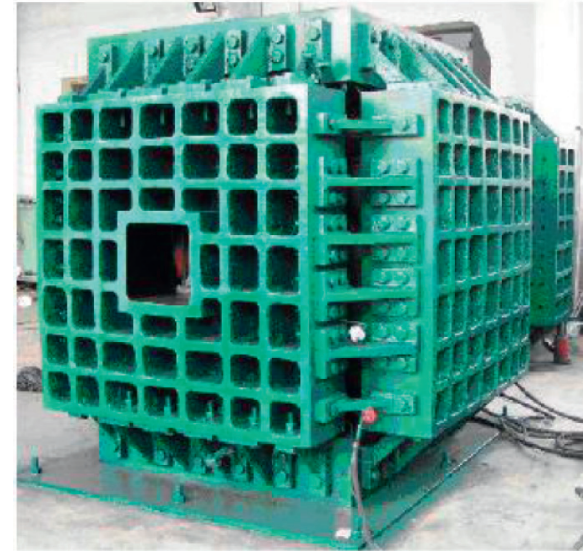

(a)

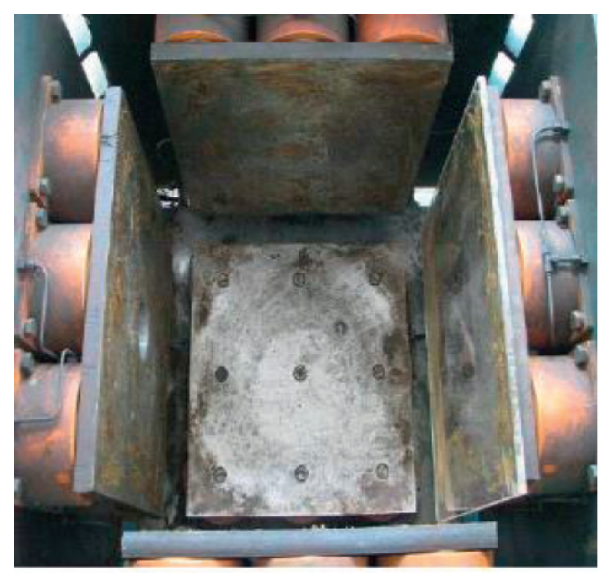

(b)

Figure 9: Comprehensive simulation testbed.

bulk density similarity ratio is $1: 1.25$, and the stress similarity ratio is $1: 125$. According to the test requirements, there are five monitoring points on the roof of roadway, four on each side and three on the floor. The layout of monitoring points is shown in Figure 10. The physical model is fabricated by layered pouring. The fabrication process mainly includes weighing raw materials, full mixing, boundary treatment, spreading and compacting, and setting bedding surface according to the ratio of simulated rock layers. Due to the influence of temperature on moisture volatilization, this experiment was carried out in the summer. After production, the model should be placed for 10 days (about 30 days in the winter under constant temperature) to completely volatilize the moisture, so that the model can be fully consolidated, and then the subsequent loading and excavation work can be carried out [34-41].

5.3.3. Model Excavation and Pressurization. Unloading the bolt and the iron plate, the hollow drill bit and twist drill pipe are used along the centreline at the distance of $100 \mathrm{~mm}$ from the bottom plate to simulate the excavation of the model, and the excavation is completed at one time. The experimental triaxial compression load is controlled by the oil circuit. Considering that the compaction process takes a certain time, in order to avoid the damage of the specimen and steel wire, the load is gradually exerted on the model. The loading values of the left and right slabs are $0.3,0.6,0.9$, 1.2 , and 1.5 times of the loading values of the upper and lower slabs, and the loading values of the upper and lower slabs are equivalent to the in situ stresses of $200-1000 \mathrm{~m}$.

A curve diagram, which is shown in Figure 11, of the effect of roadway width, height, vertical pressure (burial depth), lateral pressure coefficient, and CSSR on the roadway stability was derived from the computer analysis and processing of the data collected by DataTaker515, and the data collecting and processing system is shown in Figure 12.

Through the analysis of the data in Figure 11, it can be found that the vertical stress is the key factor affecting the

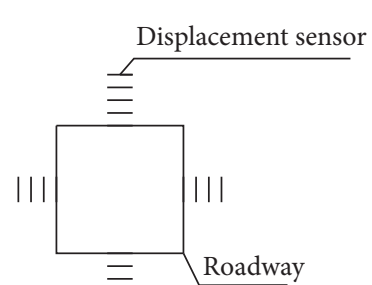

FIGURE 10: The schematic diagram of roadway monitoring spots' layout.

comprehensive deformation of the tunnel. In the similar material simulation test, with the increase of the vertical stress imposed by the three-dimensional similar material simulation test bench, the comprehensive deformation of the tunnel also shows a "steep rise." When the vertical stress increases from $0.05 \mathrm{MPa}$ to $0.25 \mathrm{MPa}$, the comprehensive deformation of the tunnel increases from $2.7 \mathrm{~mm}$ to $17.3 \mathrm{~mm}$; it increases by $540.74 \%$. With the increase of the comprehensive strength of the surrounding rock, the change trend of the comprehensive deformation of the roadway is "sudden decrease" first, and then the change tends to be gentle. The comprehensive strength of surrounding rock increased from $0.1 \mathrm{MPa}$ to $0.9 \mathrm{MPa}$, and the comprehensive deformation of surrounding rock decreased from $15 \mathrm{~mm}$ to $5.9 \mathrm{~mm}, 154.23 \%$. Through the comparative analysis of Figures 8 and 11, the influence trend of the five factors of similar material simulation test and numerical simulation test on the stability of the roadway is basically the same, and the results of the two simulation tests are basically the same.

\section{Field Practice}

The Fucun coal mine of Zaozhuang mining group has a simple geological structure and a small dip angle of coal seam. The Pugh coefficient of coal seam is $0.6 \sim 1.9$, with an average of 1.2 , and its strength is relatively low. The coal seam roof and floor are mainly composed of middle sandstone and siltstone with high strength. Due to the 


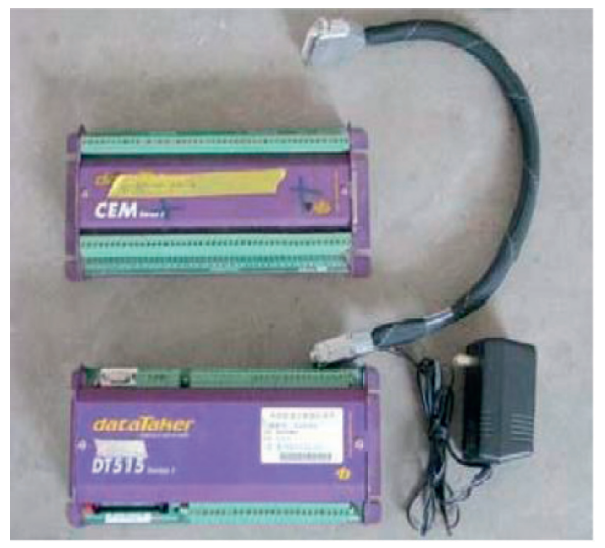

(a)

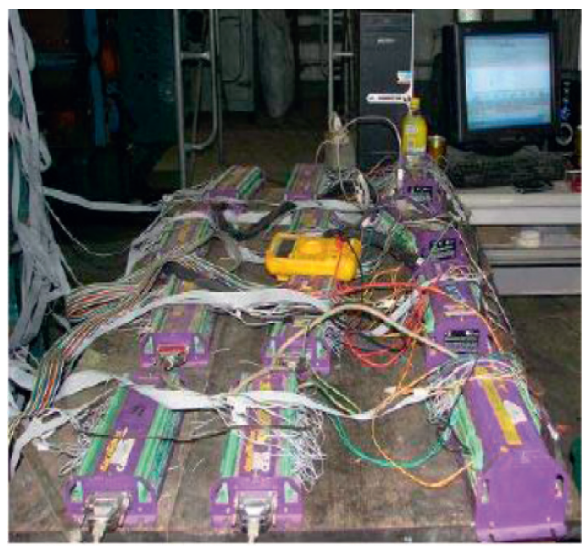

(b)

FIGURE 11: The effect of each factor on the roadway stability in the similar material simulation experiment.

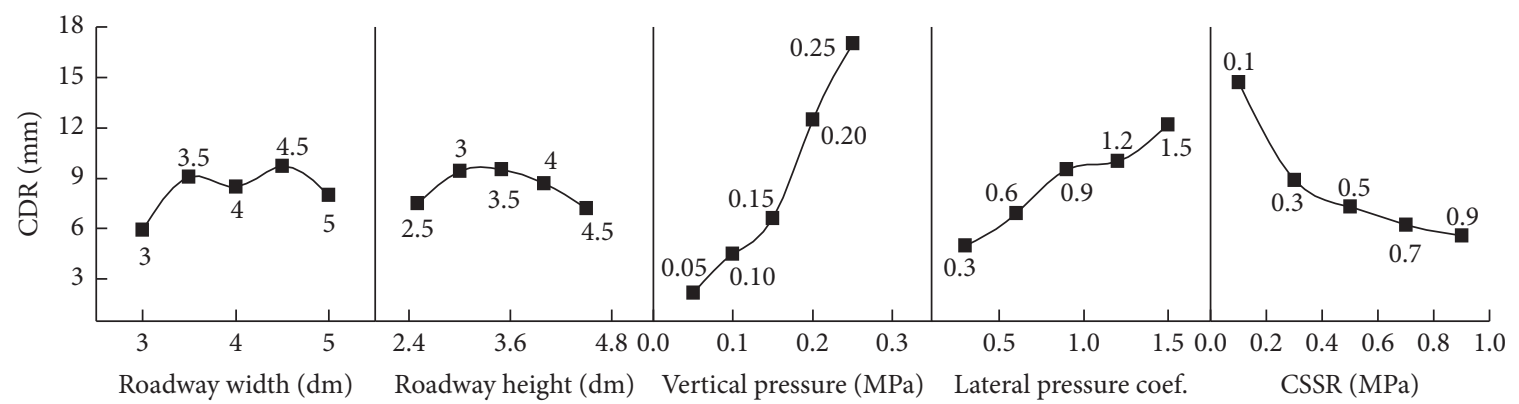

FIGURE 12: Data collecting and processing system.

TABLE 5: Depth and comprehensive stress of surrounding rock of each site.

\begin{tabular}{|c|c|c|}
\hline Depth $(\mathrm{m})$ & Test location & Comprehensive strength of surrounding rock $(\mathrm{MPa})$ \\
\hline \multirow{3}{*}{400} & 1 & 12 \\
\hline & 2 & 25 \\
\hline & 3 & 68 \\
\hline \multirow{3}{*}{600} & 4 & 7 \\
\hline & 5 & 23 \\
\hline & 6 & 53 \\
\hline \multirow{3}{*}{800} & 7 & 15 \\
\hline & 8 & 25 \\
\hline & 9 & 48 \\
\hline
\end{tabular}

limitation of mining conditions, the roadway test mainly explores the influence of the buried depth and the comprehensive strength of surrounding rocks on the comprehensive deformation of roadway. In this experiment, 9 representative test sites at 3 levels were selected. The burial depth and comprehensive strength of surrounding rocks of each test site are shown in Table 5, and the test results are shown in Figure 13.

It can be seen from Figure 13 that under the same comprehensive strength of surrounding rock, the comprehensive deformation of roadway increases with the increase of buried depth. Under the same buried depth, the comprehensive deformation of the roadway decreases with the increase of the comprehensive strength of the surrounding rock, and when the comprehensive strength of the surrounding rock is less than $40 \mathrm{MPa}$, its impact on the comprehensive deformation of the roadway is relatively large; when the comprehensive strength of the surrounding rock is greater than $40 \mathrm{MPa}$, its impact on the comprehensive deformation of the roadway is relatively weak. The field test results are basically consistent with the two simulation results, but the comprehensive deformation of the roadway is larger than that of the numerical simulation results, which is mainly due to the lack of consideration of the influence of fracture and geological structure in the rock (coal) layer during the numerical simulation process. 


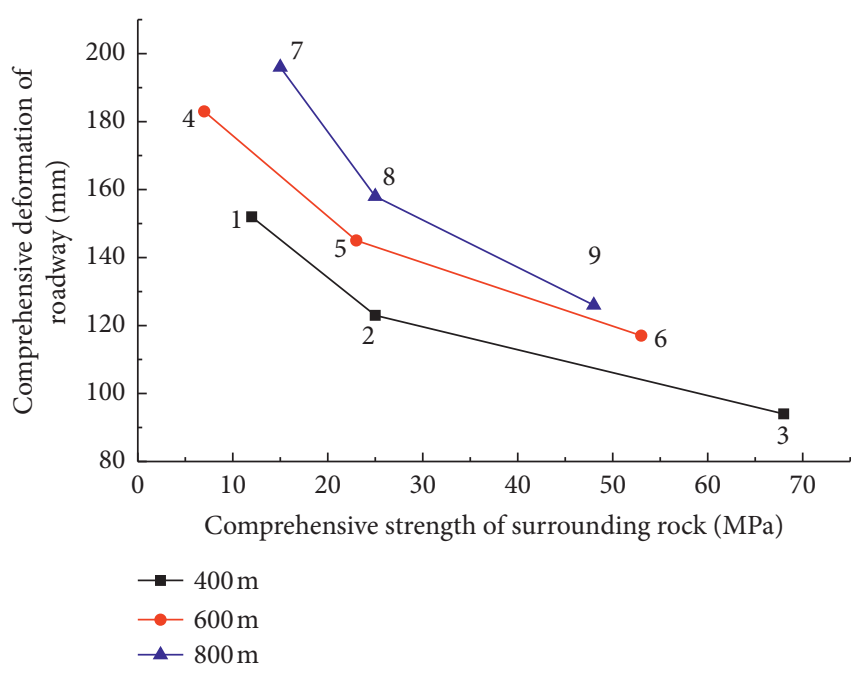

FIGURE 13: Deformation of each monitoring site.

\section{Conclusions}

(1) The comprehensive strength of surrounding rock refers to the overall strength of the roof, two sides, and floor rock mass of the roadway, reflecting the overall stability of the surrounding rock of the roadway. Through the mechanical analysis, it can be seen that the span, depth, and lateral pressure coefficient of the roadway will affect the stability of the roof, and the height of the roadway will affect the stability of the two sides. Therefore, there is a certain connection among the five factors of the roadway depth, roadway width, roadway height, lateral pressure coefficient, and comprehensive strength of the surrounding rock, which can be used as the factors to measure the stability of the roadway.

(2) The results show that the width, height, buried depth, lateral pressure coefficient, and comprehensive strength of surrounding rock all have influence on the stability of roadway, but the influence size is not the same. The sequence of the effect in descending order is burial depth $>$ CSSR $>$ lateral pressure coefficient $>$ roadway width $>$ roadway height. The buried depth and lateral pressure coefficient of roadway are positively correlated with the comprehensive deformation of roadway, while the comprehensive strength of surrounding rock is negatively correlated with the comprehensive deformation of roadway, while the correlation between the width and height of roadway and the comprehensive deformation of roadway is not obvious. The research results can provide theoretical basis for roadway support, grouting reinforcement of surrounding rock, and roadway section design in deep mines.

(3) Based on the principle of orthogonal test, the numerical simulation test and similar material simulation test schemes are developed, and the results of the two test methods are the same, and the field practice results are basically consistent with the test results. The study method is relatively mature, and the study results are more applicable to the study and practice of roadway stability in the coal mine site.

\section{Data Availability}

The authors declare that all data supporting the findings of this study are available within the article; the reader can find and use it. There are no unavailable data.

\section{Conflicts of Interest}

The authors declare that there are no conflicts of interest regarding the publication of this paper.

\section{Acknowledgments}

This paper was supported by the National Natural Science Foundation of China (nos. 51379119, 51304126, and 51109124).

\section{References}

[1] Z. L. Zeng, "Roadway on factors of laneways distorted and control methods reasonable," Coal Technology, vol. 27, no. 4, pp. 141-144, 2008.

[2] X. Y. Liao, X. H. Tan, and Q. F. Li, "Study on supporting measures and stress distribution of thick coal rectangular roadway," Mineral Engineering Research, vol. 26, no. 1, pp. 1-6, 2011.

[3] G. C. Li, N. Zhang, and C. Wang, "Optimizing the section shape of roadways in high stress ground by numerical simulation," Journal of China University of Mining \& Technology, vol. 39, no. 5, pp. 652-658, 2010.

[4] H. P. Kang, "Flac analysis on affecting aactors to rock bolting in gateroads," Chinese Journal of Rock Mechanics and Engineering, vol. 18, no. 5, pp. 534-537, 1999.

[5] Y. B. Li, Y. K. Yang, and X. G. Su, "Study on the stability of surrounding rocks of a coal roadway in different depth," Journal of Taiyuan University of Technology, vol. 42, no. 6, pp. 603-606, 2011.

[6] H. W. Jing, Y. H. Li, and G. A. Xu, "Analysis of surrounding rock stability of deeply buried roadways and study on its control techniques," Rock and Soil Mechanics, vol. 26, no. 6, pp. 877-880, 2005.

[7] C. J. Hou and N. J. Ma, "Stress in in-seam roadway sides and limit equilibrium zone," Journal of China Coal Society, vol. 14, no. 4, pp. 21-29, 1989.

[8] S. B. Xu, The Principle of Analytical Hierarchy Process, Tianjin Press, Tianjin, China, 1988.

[9] M. L. Shen and J. F. Chen, Rock Mass Mechanics, Tongji University Press, Shanghai, China, 2006.

[10] Y. L. Tan, S. L. Wu, and Z. D. Yin, Ground Pressure and Strata Control, China Coal Industry Publishing House, Beijing, China, 2008.

[11] Y. M. Dou, J. N. Wang, G. Z. Tian, J. W. Li, and M. Wei, "Application of analytic hierarchy process in orthogonal test of soil similar materials," Sichuan Architectural Science Research, vol. 43, no. 4, pp. 59-63, 2017.

[12] S. W. Wang, Y. X. Gao, and L. Zhang, "Study on Numerical Simulation of heat dissipation system of permanent magnet synchronous motor based on orthogonal test method," Motor and Control Applications, vol. 43, no. 11, pp. 103-107, 2016. 
[13] Q. J. Ren, H. Q. Wan, and X. Y. Wang, "Orthogonal experiment and numerical simulation of milling force of gun steel," Ordnance Automation, vol. 35, no. 9, pp. 41-44, 2016.

[14] D. Q. Zhang, Y. Q. Yu, and C. P. Mu, "Sensitivity analysis of influencing factors of pillar stability based on orthogonal test," Modern Mining, vol. 31, no. 5, pp. 11-13, 2015.

[15] X. J. Li, R. F. Yuan, and X. D. Zhao, "Numerical simulation of surrounding rock failure law of rectangular roadway," Mining Engineering, vol. 6, no. 2, pp. 18-20, 2008.

[16] Y. X. Yu and S. C. Gu, "Study on measurement and control technology of surrounding rock loosening range of rectangular roadway," Journal of Mining and Safety Engineering, vol. 30, no. 6, pp. 828-835, 2013.

[17] T. C. Li, Z. Lu, and J. Z. Liu, "Deformation and failure process analysis of rectangular roadway in muddy weak cemented soft rock strata," Geotechnical Mechanics, vol. 35, no. 4, pp. 1077-1083, 2014.

[18] X. L. Liu, M. M. Wang, and X. Y. Wang, "Stability numerical analysis of deep rock roadway based on orthogonal test," Coal Science and Technology, vol. 46, no. 2, pp. 138-143 + 181, 2018.

[19] X. Huang, H. N. Ruan, and X. W. Wang, "Stability analysis and control of deep soft rock roadway under different lateral pressure coefficients," China Coal, vol. 44, no. 7, pp. $59-63+87,2018$.

[20] Y. H. Zhu, "Stability analysis of surrounding rock of roadway based on stress intensity," Coal Science and Technology, vol. 46, no. S1, pp. 54-57, 2018.

[21] C. Liu, Y. X. Li, and T. Min, "Study on optimization of roadway stability based on three-dimensional in-situ stress measurement," Journal of Underground Space and Engineering, vol. 14, no. 5, pp. 1372-1380, 2018.

[22] Z. P. Jia, J. Hou, and L. H. Zheng, "Study on the influence of deep tectonic stress on roadway stability," Gold, vol. 39, no. 11, pp. 35-39, 2018.

[23] G. H. Wen, X. S. Li, and Q. L. Chang, "Stability analysis of surrounding rock affected by lateral abutment pressure in goaf," Coal Technology, vol. 35, no. 11, pp. 16-18, 2016.

[24] X. Y. Liu, Y. C. Ye, and Q. H. Wang, "The numerical simulation study on the influence of Poisson's ratio on roadway stability," China Safety Production Science and Technology, vol. 12, no. 12, pp. 80-85, 2016.

[25] X. Y. Liu, Y. C. Ye, and Y. Liu, "Evaluation of roadway stability based on unascertained measurement theory," Journal of Safety and Environment, vol. 17, no. 1, pp. 26-31, 2017.

[26] R. Peng, Z. H. Ouyang, and X. R. Meng, "Acoustic emission testing of non-uniform stress field near reverse fault and numerical analysis of tunnel stability," Journal of Geotechnical of Geotechnical Engineering, vol. 41, no. 3, pp. 509-518, 2019.

[27] Y. Wang, "The influence of different parameters on the stability of surrounding rock of roadway with coal roof," $R e$ source Information and Engineering, vol. 32, no. 6, pp. 83-84, 2017.

[28] C. M. Li and W. R. Liu, "Particle discrete element analysis of surrounding rock stability of jointed rock roadway," Chinese Journal of Safety Sciences, vol. 27, no. 04, pp. 133-138, 2017.

[29] J. Y. Tian, Study on Optimization of Support for Rectangular Coal Roadway under Horizontal Stress, Kunming University of Technology, Kunming, China, 2017.

[30] K. Li, H. L. Gu, and K. P. Qiu, "The numerical simulation analysis of the influence of roadway size on the stability of surrounding rock," Coal Technology, vol. 35, no. 03, pp. 52-54, 2016.
[31] Z. J. Zhu, H. W. Zhang, and J. Han, "Study on roadway stability under different stress fields," China Safety Production Science and Technology, vol. 11, no. 11, pp. 11-16, 2015.

[32] R. B. Hou, Z. F. Wang, and Y. Q. Zhang, "The influence of lateral pressure coefficient on the stability of arch roadway with semi-circular straight wall," Mining Research and Development, vol. 35, no. 10, pp. 51-54, 2015.

[33] C. D. Tian and H. B. Bai, "Analysis of the influence of roadway size and layout on surrounding rock stability," Coal Mine Safety, vol. 46, no. 8, pp. 220-223, 2015.

[34] X. Y. Sun, G. G. Kou, and P. Q. Li, "Similar simulation experiment of overlying strata movement under repeated mining," Coal Technology, vol. 37, no. 9, pp. 12-14, 2018.

[35] Y. K. Cao, J. S. Zhang, and J. Ren, "Experimental study on similar materials ratio of $3 \sim \#$ coal seam mining in Shiquan Mine," Coal Technology, vol. 37, no. 8, pp. 10-11, 2018.

[36] Z. W. Zhao, Experimental Study on Shale Similar Material Proportioning Based on Response Surface Method, Wuhan University of Science and Technology, Wuhan, China, 2018.

[37] Q. Yao, T. Feng, W. J. Wang, Z. Liao, and C. F. Ma, "Mixing ratio and mechanical test of similar materials for mining," Journal of Safety and Environment, vol. 17, no. 6, pp. 21292134, 2017.

[38] J. Gao and S. H. Zhang, "Brief analysis on the development and prospect of similar simulation experiment of mine physical materials," Mining Research and Development, vol. 37, no. 7, pp. 73-78, 2017.

[39] S. Chen, D. Zhang, and Q. Yuan, "Monitoring and correction of the stress in an anchor bolt based on pulse prepumped brillouin optical time domain analysis," Energy Science \& Engineering, vol. 1, pp. 1-13, 2020.

[40] Z. Wen, E. Xing, S. Shi, and Y. Jiang, "Overlying strata structural modeling and support applicability analysis for large mining-height stopes," Journal of Loss Prevention in the Process Industries, vol. 57, pp. 94-100, 2018.

[41] X. Wang, Z. Wen, Y. Jiang, and H. Huang, "Experimental study on mechanical and acoustic emission characteristics of rock-like material under non-uniformly distributed loads," Rock Mechanics and Rock Engineering, vol. 51, no. 3, pp. 729-745, 2018. 